Revue

d'ethnoécologie
Revue d'ethnoécologie

19 | 2021

Varia

\title{
À noter
}

\section{La rédaction}

\section{(2) OpenEdition}

Journals

Édition électronique

URL : https://journals.openedition.org/ethnoecologie/7064

DOI : $10.4000 /$ ethnoecologie.7064

ISSN : 2267-2419

\section{Éditeur}

Laboratoire Éco-anthropologie

\section{Référence électronique}

La rédaction, «À noter », Revue d'ethnoécologie [En ligne], 19 | 2021, mis en ligne le 30 juin 2021 , consulté le 17 décembre 2021. URL : http://journals.openedition.org/ethnoecologie/7064 ; DOI https://doi.org/10.4000/ethnoecologie.7064

Ce document a été généré automatiquement le 17 décembre 2021.

\section{(c) $($ i) $(9)$}

Revue d'ethnoécologie est mis à disposition selon les termes de la licence Creative Commons Attribution - Pas d'Utilisation Commerciale - Pas de Modification 4.0 International. 


\section{À noter}

\section{La rédaction}

1 Comme rappelé dans le numéro 18, Françoise Aubaile-Sallenave avait pris l'initiative, à l'été 2018, de réunir en hommage à Serge Bahuchet, des textes de chercheurs ayant tous travaillé de près ou de loin avec lui, dans l'optique interdisciplinaire. Son idée était alors de publier ces Mélanges dans la Revue d'Ethnoécologie. Comme ces articles comportaient, à des degrés divers, des références personnelles et des marques d'amitié inhabituelles dans une revue scientifique, il a été convenu de reprendre dans les numéros 18 et 19 de la Revue d'Ethnoécologie ceux de ces articles qui s'inscrivent le mieux dans la perspective pluridisciplinaire de la revue et de laisser toute son originalité et son intégrité au liber amicorum édité par Françoise Aubaile en marge de la revue.

2 En complément des premiers articles déjà repris dans le numéro 18, figurent dans ce numéro 19, les articles écrits par Marina Quiñe, par Philippe Chambon, Pascal Sellier, Aline Emery-Barbier et Olivier Langlois, par Céline Bon et Marie-Claude MarsolierKergoat et par Marie Fleury, Aimawale Opoya, Aitalewa Palanaiwa, Anaima Putpu, Daniel Sabatier et Martijn van den Bel.

3 Retrouver l'ouvrage complet sur le site de l'UMR 7206 Eco-anthropologie

https://www.ecoanthropologie.fr/fr/le-melomane-et-lhumaniste-9245 